\title{
The Impact of Personality Type on Techno stress: A Study among the Library Professionals of Engineering Colleges of Anna University of Technology, Coimbatore
}

\author{
Dr.K.Mahalakshmi ${ }^{1}$ \\ Librarian,Faculty of Engineering,Avinashilingam \\ University, Thadagam \\ P.O.,Coimbatore,Tamilnadu,India \\ E-mail: nilamaha@gmail.com
}

\author{
Dr.S.AllySornam ${ }^{2}$ \\ Associate Professor \& Head,PG \& Research DLIS \\ Bishop Heber College \\ Tiruchirappalli,Tamilnadu,India \\ E-mail: ally_jelen@yahoo.co.in
}

\begin{abstract}
The technological revolution of this decade ha-s certainly brought about many changes in the functioning of libraries nowadays. Although it has allowed work to be carried out faster and more efficiently, many library professionals are not comfortable with the implementation of technology as it involves change and uncertainty. As a result, they develop additional stress known as techno stress which may have negative impact in the activities of libraries.

This study intends to find out the relationship between the personality type and techno stress among library professionals of engineering colleges of Anna University Technology, Coimbatore based on a questionnaire, comprising of demographic factors and personality type and techno stress of the respondents. The results of the study are presented with suitable hypotheses and relevant interpretation.
\end{abstract}

Keywords- Personality type, Techno stress, Library Professionals, Engineering Colleges

\section{INTRODUCTION}

Today's persistent information and communication technology enable us to get connected almost anywhere at any time. ICT, such as internet, advanced wireless technologies and mobile communication networks are becoming increasingly indispensable in many aspects of work and everyday life. But to keep pace with advancing new technology, library professionals have to constantly renew their technical skills as well as endure pressures and higher expectations from management and users. There has been long-term interest in the processes that influence human-computer interaction, particularly those causing stress. Brod (1984) [1] refers to this type of stress as "techno stress." He indicated that techno stress is a modern disease of adaptation caused by an inability to cope with new computer technologies in a healthy manner. Some studies suggest that different aspects of technology produce greater stress for different kinds of people. Moreland (1993) [2] relates different psychological types to the various sources of stress and indicates that some people need structured learning environments while others need room to simply experiment with a new technology. In this paper, the relationship between personality type and techno stress among the library professionals of Anna university technology is assessed and tested to identify the personality type that suffers greater techno stress.

\section{LITERATURE REVIEW}

A search of the literature dealing with techno stress and personality type gave the following studies

In an era, when many academic libraries were in their initial technology acquisition phase, Jones (1988) [3] conducted a survey of support staff perceptions in three university libraries - the University of California at Santa Barbara, Northern Illinois University at Dekalb, and the University of Richmond. On the verge of a computer technology revolution, her research sought to analyze the assimilation process experienced by the library workers. The overall survey indicated a positive attitude coupled with undercurrents of personal frustration and irritation.

Ten years Later: Support staff perceptions and opinions on technology in the workplace (Jones, 1999) [4] presented the results of Jone's 1988 follow-up survey of the sample group. In addition to surveying perception of the support staff, the questions added were: Internet usage, health issues and two questions related to stress were included. The pressure to keep up had intensified; there was still a gap in training, and new health /Stress anxieties over computer-related ailments surfaced. In the 1998 survey, respondents' attention shifted from automation in cataloguing/technical services to an emphasis on technological advancements in reference /research departments. Upon discovering that only $25 \%$ of support staff personnel were included in library technology planning and decision making, Jones argued strongly on behalf of their involvement. She observed that: Change in the magnitude we are now experiencing is almost sure to cause turbulence. Collegial understanding among all members of a library staff, if carefully fostered, can certainly minimize trouble and maximize the much strength available to make technological transitions smoother.

Virginia Moreland (1993) [5] in her article "techno stress and personality type" emphasized that the different aspects of technology produce greater stress for different 
personality types. People learn differently, and these differences also have to be taken into account to reduce the techno stress. Myers-Briggs type indicator (MBTI) produces sixteen possible personality types.

Margaret Gaff's (1994) [6] article "GUI vs. CUI: Individual personality types and the experience of learning to use library databases" focuses on how certain personality types have more difficulty in using CUI (Character User Interface) than GUI (Graphical User Interface). Gaff conducted a pilot study with a sample of five participants. The personality types represented primarily introverts. Databases were selected that were both character and graphics based. The results were that all five participants found that the GUI is easy to use. Three out of five found CUI frustrating, one found it challenging and the last found it child's play. This participant was an ISTJ personality type with a thinking dominance.

Coming to the study area, Ally Sornam (2003) [7] in her work titled " A study on job stress among university library professionals in Tamil Nadu" identified personality pattern of library professionals and it is observed that majority of the library professionals $(68.3 \%)$ have Type A behaviour pattern. $15.8 \%$ belong to Type $\mathrm{AB}$ and the rest (15.8\%) formed Type B pattern. Type A behaviour pattern revealed significant difference at the organizational and overall stress level.

\section{OBJECTIVES}

The objective is to find out the relation between different personality type and techno stress among library professionals of engineering colleges of Anna University Technology, Coimbatore, Tamil Nadu based on a questionnaire comprising of demographic factors and personality type and stress of the participants.

\section{PERSONALITY TYPE}

The link between personality type and stress was discovered in the early 1960's by Meyer Friedman and Ray Rosenman,[8] two American cardiologists. Type A behavior is characterized by an intense and sustained drive to achieve goals and an eagerness to compete. Personalities categorized as Type A tend to have a persistent desire for external recognition and advancement. They are involved in various functions that bring about time restrictions Such personalities have a tendency to speed up mental and physical tasks with extraordinary mental and physical alertness. Type B personalities are relaxed and have a laidback attitude and posture. They are friendly, accepting, patient, at ease, and generally content. They are at peace with themselves and others. They show a general sense of harmony with people, events, and life circumstances. They tend to be trusting. They focus on the positive aspects of people and events. Type B folks are self-encouraging, have inner motivation, are stable and have a pleasant mood. They are interested in others and accept small mistakes too. The Type B person is able to lead better than Type A Person.

\section{METHODOLOGY}

Anna University was established on 4th September 1978 as a unitary type of University[9]. In the year 2002, it was converted into an affiliated type of University wherein all the Government, Government aided and Self-financing Engineering Colleges in the State of Tamil Nadu numbering around 102 are taken under one umbrella. There were 240 engineering colleges during 2006. Due to administrative exigencies, the state government divided the Anna University into the four separate universities,

- Anna University, Chennai

- Anna University of Technology, Coimbatore

- Anna University of Technology, Tiruchirappalli

- Anna University of Technology, Tirunelveli and

- Anna University of Technology, Madurai

In studying the impact of personality type on techno stress among library professionals of Anna University of Technology, Coimbatore is selected as the study area. At the time of study, Anna University of technology, Coimbatore has 135 affiliated colleges of which 32 colleges were started only two years back. These colleges being relatively new were not included in this study. In order to ascertain the opinion from the professionals (Librarians and Assistant Librarians) from the affiliated colleges of Anna University of Technology, Coimbatore, a questionnaire was constructed in consultation with the experts in the relevant fields. It is divided into two parts. First part of the questionnaire comprises demographical data of the respondents such as age, gender, educational qualification, total library experience, area of specialization, type of the institution, nativity, marital status, monthly income and the second part concentrates on personality type of the respondents. A complete enumeration method was adopted to get the opinion from the respondents. The questionnaire was sent to 103 professionals (32 colleges were omitted) during the month of February, 2010. The respondents were assured that their identity will be kept confidential. Out of 103 filled questionnaires, only 98 were found to be defect free in all aspects even after frequent follow ups. So, the revised population for the study is 98 and the collected data were processed and analyzed using SPSS software.

TABLE I. DEMOGRAPHIC DETAILS

\begin{tabular}{|c|c|c|c|}
\hline $\begin{array}{c}\text { Demographic } \\
\text { variable }\end{array}$ & Classification & Frequency & Percentage \\
\hline Gender & Male & 71 & 72.4 \\
& Female & 27 & 27.6 \\
\hline Age & $<25$ & 5 & 5.1 \\
(in years) & $25-34$ & 51 & 52.0 \\
& $35-44$ & 33 & 33.7 \\
& $45-54$ & 8 & 8.2 \\
& $55+$ & 1 & 1.0 \\
\hline Marital & Bachelor/Spinster & 23 & 23.5 \\
Status & Married & 73 & 74.5 \\
& Divorced & - & - \\
& Widow & 2 & 2.0 \\
\hline Educational & Bachelors in LIS & 2 & 2.0 \\
Qualification & Other Bachelor & & \\
\hline
\end{tabular}




\begin{tabular}{|c|c|r|r|}
\hline & Degree & 13 & 13.3 \\
& Masters in LIS & & \\
& Other Master's & 17 & 17.3 \\
& Degree & 4 & 4.1 \\
& M.Phil & 54 & 55.1 \\
& Ph.D. & 8 & 8.2 \\
\hline Total library & $1-5$ & 33 & 33.7 \\
Experience & $6-10$ & 34 & 34.7 \\
(in Years) & $11-15$ & 18 & 18.4 \\
& $16-20$ & 6 & 6.1 \\
& $21-25$ & 6 & 6.1 \\
& $26-30$ & - & - \\
& $31+$ & 1 & 1.0 \\
\hline Institution & Govt & 3 & 3.1 \\
type & Govt-Aided & 2 & 2.0 \\
& Self- Financing & 86 & 87.8 \\
& Autonomous & 7 & 7.1 \\
& & & \\
\hline Monthly & Below Rs.10,000 & 43 & 43.9 \\
Income & Rs.10,001-20,000 & 39 & 39.8 \\
& Rs.20,001-30,000 & 11 & 11.2 \\
& Rs.30,001-40,000 & 3 & 3.1 \\
& Rs.40,001-50,000 & 1 & 1.0 \\
& Rs.50,001-60,000 & -- & - \\
& Rs.60,001+ & 1 & 1.0 \\
\hline Nativity & Urban & 41 & 41.8 \\
& Rural & 57 & 58.2 \\
& & & \\
\hline
\end{tabular}

Table I provides information about the demographic details of the respondents. There were 98 respondents who answered to this questionnaire. 71 were male $(72.4 \%)$ and female were $27(27.6 \%)$. Majority were in the age group of $25-34(52.0 \%)$, followed by $35-44$ group (33.7\%), $45-54$ were $(8.2 \%)$. Freshers below 25 were $(5.1 \%)$ and above 55 were $(1.0 \%)$. Thus the chunk of the largest group was between 25-34, people in the middle of their lives. Most of respondents $(74.5 \%)$ were married and $24.5 \%$ were unmarried and very few $(2.0 \%)$ respondents were widow. $(34.7 \%)$ respondents have 6-10 years of total library experience, $(33.7 \%)$ have $1-5$ years of experience, $(18.4 \%)$ respondents have 11-15 years of experience, $(6.1 \%)$ have 16-20 years and 21-25 years each and (1.0\%) of the respondent have above 31 years of experience. Majority of the respondents worked in self financing $(87.8 \%),(3.1 \%)$ in government and $(2.0 \%)$ in government aided and $(7.1 \%)$ in autonomous institutions. About $(43.9 \%)$ participants were drawing monthly salary below Rs.10, 000, (39.8\%) were drawing between Rs.10, 001-Rs 20, 000, (11.2. \%) were earning between Rs.20, 001-Rs.30, 000, (3.1\%) were drawing Rs.30, 001-Rs.40, 000 and $(1.0 \%)$ of the respondent was earning Rs.40, 001-Rs.50, 000 and above Rs.60, 001 respectively. (58.2. \%) respondents were from rural area and $(41.8 \%)$ were from urban.

TABLE 2

PERSONALITY TYPE
AND TECHNOSTRESS

\begin{tabular}{|c|c|c|c|c|c|c|c|c|c|c|}
\hline \multirow{2}{*}{$\begin{array}{l}\text { Persona } \\
\text { lity } \\
\text { Type B }\end{array}$} & \multicolumn{6}{|c|}{$\begin{array}{c}\text { Responses (In } \\
\text { percentage) }\end{array}$} & 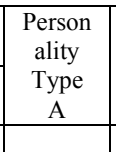 & $\begin{array}{l}Z \\
\text { Valu } \\
\mathrm{e}\end{array}$ & $\begin{array}{c}\text { P } \\
\text { va } \\
\text { lu } \\
\mathrm{e} \\
\end{array}$ & $\begin{array}{c}\mathrm{NS} / \\
\mathrm{S}\end{array}$ \\
\hline & - & $\sim$ & $m$ & $\nabla$ & in & b) & $\infty$ & & & \\
\hline 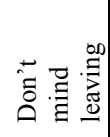 & $\overrightarrow{6}$ & $\stackrel{\infty}{\infty}$ & $\stackrel{m}{m}$ & F & $\stackrel{?}{ \pm}$ & $\hat{n}$ & 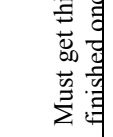 & $\begin{array}{l}\stackrel{+}{n} \\
\tilde{n} \\
i\end{array}$ & 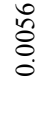 & is \\
\hline 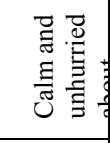 & $\vec{n}$ & $\overrightarrow{0}$ & $\stackrel{\simeq}{=}$ & $\stackrel{\text { o̊ }}{0}$ & $\stackrel{m}{m}$ & $\stackrel{n}{2}$ & 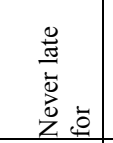 & $\frac{\stackrel{a}{a}}{\stackrel{i}{i}}$ & $\begin{array}{l}\stackrel{0}{1} \\
0 \\
0 \\
0\end{array}$ & us \\
\hline 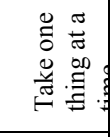 & $\stackrel{?}{=}$ & है & $?$ & $\stackrel{\sim}{=}$ & $\overrightarrow{6}$ & $\stackrel{m}{m}$ & 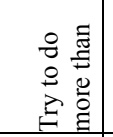 & $\begin{array}{l}\stackrel{9}{9} \\
\stackrel{2}{\leftrightarrows}\end{array}$ & \begin{tabular}{l}
\multirow{6}{0}{} \\
$=$ \\
0
\end{tabular} & $\tilde{Z}$ \\
\hline$\sum_{\Sigma}^{\overrightarrow{0}} \pi$ & $\stackrel{\sim}{=}$ & $\infty$ & $\stackrel{?}{+}$ & $\stackrel{n}{ \pm}$ & $\stackrel{m}{m}$ & $\stackrel{m}{m}$ & ठี & $\begin{array}{l}\sqrt{n} \\
0 \\
0\end{array}$ & \begin{tabular}{l}
$n$ \\
\multirow{2}{*}{} \\
0
\end{tabular} & $\tilde{Z}$ \\
\hline 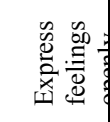 & $\stackrel{?}{=}$ & ㄱ. & $\stackrel{ }{a}$ & $\stackrel{m}{ \pm}$ & $\stackrel{1}{\varrho}$ & 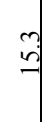 & 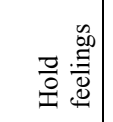 & 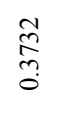 & $\begin{array}{l}n \\
n \\
n \\
0\end{array}$ & $\tilde{z}$ \\
\hline 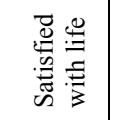 & $\stackrel{m}{m}$ & $\overrightarrow{7}$ & $\stackrel{\sim}{\sim}$ & $\stackrel{\sim}{=}$ & $\vec{n}$ & $\stackrel{\nabla}{\Delta}$ & 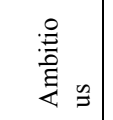 & 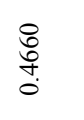 & $\begin{array}{l}\stackrel{0}{1} \\
\text { ?ै} \\
0\end{array}$ & $\Sigma_{Z}$ \\
\hline 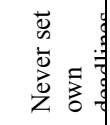 & $\stackrel{\sim}{=}$ & in. & $\stackrel{?}{a}$ & $\stackrel{\sim}{=}$ & $\stackrel{m}{m}$ & $\stackrel{+}{\dot{0}}$ & 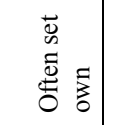 & : & $\begin{array}{l}\hat{n} \\
\hat{n} \\
0\end{array}$ & $\tilde{Z}^{\Omega}$ \\
\hline 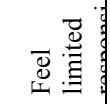 & $\stackrel{\sim}{\circ}$ & $\Rightarrow$ & $\overrightarrow{7}$ & $\stackrel{\text { İ }}{\mathrm{I}}$ & $\stackrel{1}{\varrho}$ & $\stackrel{n}{\sim}$ & 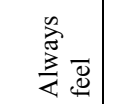 & $\begin{array}{l}0 \\
\stackrel{0}{\infty} \\
\stackrel{\infty}{+} \\
i\end{array}$ & $\begin{array}{l}\circ \\
\stackrel{0}{8} \\
\stackrel{0}{0}\end{array}$ & n \\
\hline 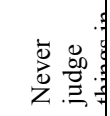 & הి & ?7? & $\stackrel{ก}{3}$ & $\stackrel{\Upsilon}{0}$ & $\vec{m}$ & $\stackrel{\simeq}{0}$ & 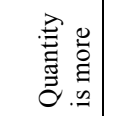 & $\begin{array}{l}\vec{n} \\
\stackrel{\infty}{+} \\
i\end{array}$ & $\begin{array}{l}2 \\
8 \\
0 \\
0\end{array}$ & is \\
\hline 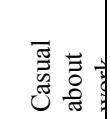 & 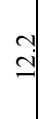 & 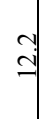 & $\stackrel{?}{0}$ & $\stackrel{m}{m}$ & $\stackrel{?}{\varrho}$ & $\stackrel{m}{ \pm}$ & 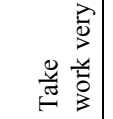 & $\frac{\bar{a}}{\grave{2}}$ & $\begin{array}{l}n \\
n \\
\infty \\
n \\
0\end{array}$ & $\tilde{Z}$ \\
\hline$\frac{3}{\infty} \cdot \frac{0}{0}$ & $\overrightarrow{6}$ & $\vec{n}$ & $\vec{n}$ & $\stackrel{N}{=}$ & $\stackrel{m}{n}$ & $\stackrel{n}{n}$ & 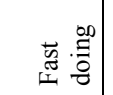 & 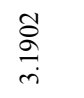 & $\begin{array}{l}\hat{8} \\
8 \\
0\end{array}$ & us \\
\hline
\end{tabular}

Hypothesis 1: Fgrrsonality types of the respondents have no significant influence on Techno stress.

It is found from taSle 2 that hypothesis 1 is accepted (Not Significant) in all the dases except casual about work, take one thing at a time, relaxed, setting deadline, ambitious and 
expression of feelings openly. No responses and neutral value have been removed from the table 2. A maximum of $36.7 \%$ of the respondents have the feeling of must get things finished once started, whereas a minimum of $8.2 \%$ felt that they don't mind leaving things unfinished temporarily. A maximum of $17.3 \%$ of the respondents felt that they express their feeling openly and a minimum of $9.2 \%$ of the respondents were not expressing their feelings openly. A maximum of $23.5 \%$ of the participants are never late for appointments whereas a minimum of $5.1 \%$ are calm and unhurried about appointments.

TABLE 3 RESULTS OF CORRELATION ANALYSIS

\begin{tabular}{|c|c|c|c|c|}
\hline \multicolumn{2}{|c|}{$\begin{array}{l}\text { Dersonality } \\
\text { Type }\end{array}$} & $\begin{array}{c}\text { Age (In } \\
\text { Years) }\end{array}$ & $\begin{array}{l}\text { Experience } \\
\text { (In Years) }\end{array}$ & $\begin{array}{l}\text { Monthly } \\
\text { Income } \\
\text { (In } \\
\text { Rupees) }\end{array}$ \\
\hline \multirow[t]{2}{*}{ Working Style } & A & -0.242 & -0.292 & $-0.452^{*}$ \\
\hline & B & 0.201 & 0.202 & 0.246 \\
\hline \multirow[t]{2}{*}{ Appointment } & A & -0.053 & -0.033 & 0.021 \\
\hline & B & 0.038 & 0.163 & 0.202 \\
\hline \multirow[t]{2}{*}{ One thing at a time } & A & -0.176 & -0.200 & -0.122 \\
\hline & B & 0.272 & 0.164 & 0.48 \\
\hline \multirow[t]{2}{*}{ Mental Character } & A & 0.212 & 0.153 & 0.032 \\
\hline & B & 0.211 & $0.338^{*}$ & 0.032 \\
\hline \multirow[t]{2}{*}{ Expressing feelings } & A & 0.016 & 0.013 & -0.063 \\
\hline & B & -0.058 & -0.075 & -0.254 \\
\hline \multirow[t]{2}{*}{ Life Style } & A & $-0.423^{*}$ & -0.224 & -0.254 \\
\hline & B & 0.073 & 0.116 & 0.217 \\
\hline \multirow[t]{2}{*}{ Deadline } & A & -0.378 & -0.318 & -0.228 \\
\hline & B & -0.114 & -0.192 & -0.296 \\
\hline \multirow[t]{2}{*}{ Responsibility } & A & 0.356 & -0.031 & -0.035 \\
\hline & B & 0.147 & 0.224 & 0.290 \\
\hline \multirow[t]{2}{*}{ Quality } & A & -0.045 & -0.128 & -0.137 \\
\hline & B & 0.101 & 0.216 & 0.093 \\
\hline \multirow[t]{2}{*}{ Work attitude } & A & -0.201 & -0.06 & -0.091 \\
\hline & $\mathrm{B}$ & 0.183 & 0.224 & 0.251 \\
\hline \multirow[t]{2}{*}{ Speed } & A & 0.154 & 0.215 & 0.017 \\
\hline & B & 0.109 & 0.217 & 0.248 \\
\hline
\end{tabular}

Hypothesis 2: There is no significant difference between the personality type A and Personality type B on various aspects relating to techno stress.

It is found from the results of $\mathrm{Z}$ test that among the eleven aspects relating to Techno stress, on five aspects, there exists a significant difference $(p$ value $<0.05)$ between Type A and Type B. The Table 3 describes the results of correlation analysis carried out between three important demographic variables and personality type such as Type A \& Type B.Significant correlation exists between salary and working style of the respondents belonging to personality type A.. Significant correlation exists between Age and life styles of the respondents belong to personality type A. Significant correlation exists between experience and mental feeling of the respondents belong to personality type B. In all other cases there exists no significant relationship.

\section{CONCLUSION}

In this paper, the results of the study, conducted based on the opinion of 98 library professionals working in Anna University Technology, Coimbatore relating to personality type and techno stress are presented. It is concluded that, among the dual personality types discussed, there is no significant difference in the level of techno stress between the respondents of personality types. Further, age and life style, income and working style, experience and mental feeling of the professionals have significant relationship with techno stress. This study may be carried out for other universities and can be extended at State/National Level.

\section{REFERENCES}

[1] Brod, C. 1984. Techno stress: The human cost of computer revolution, Reading, MA. Addison-Wesley: 16

[2] Moreland, Virginia .1993.'Techno stress and personality type". Online, Vol 17(July): 59-62.

[3] Jones, Dorothy.E.1989."Library Support Staff and Technology: Perceptions and Opinions". Library Trends, Vol 37, No.4, spring: 432-56.

[4] Jones, Dorothy.E.1999. "Ten Years Later: Support Staff Perceptions and Opinions on Technology in the Workplace". Library Trends, Vol 47, No.4, spring: 711-745.

[5] Moreland, Virginia .1993."Techno stress and personality type". Online, Vol 17(July): 59-62.

[6] Gaff, Margaret.1994."GUI vs CUI: Individual personality types and the experience of learning to use library databases". Australian Library journal, Vol. 43(August):183-191.

[7] Ally sornam,S (2003).A study on Job Stress among University Library Professionals in Tamilnadu.Bharathidasan University, Tiruchy. (Unpublished Thesis).

[8] Meyer Friedman and Ray Rosenman personalitytesting.info/tests/AB.php

[9] Anna University, Chennai. www.annauniv.edu 